\title{
Práticas educativas de educadoras(es) da Escola família Agrícola "Zé de Deus" em Colinas do Tocantins (TO) 1
}

\author{
Educational practices of educators from the "Zé de Deus" Agricultural Family \\ School at Colinas do Tocantins (TO)
}

DANTAS, Alinne Conceição Alves Silva²
NAKASHIMA, Rosária Helena Ruiz ${ }^{3}$
ALMEIDA, Rejane Cleide Medeiros de ${ }^{4}$

\section{RESUMO}

O objetivo do artigo é apresentar reflexões sobre as práticas educativas de educadoras/es da Escola Família Agrícola (EFA) "Zé de Deus", localizada no município de Colinas do Tocantins, no estado de Tocantins. O percurso metodológico da pesquisa tem como método a História oral, com narrativas de histórias de vida de seis professores. Como resultados, identificamos que, para se lecionar na EFA foi necessário lidar com novas propostas escolares e com metodologias de ensino mais adequadas ao contexto campesino. Os/as professores/as narraram que, ao entrarem em contato com a realidade da EFA "Zé de Deus", aprenderam sobre a importância da educação dialógica, como base para a Pedagogia da Alternância; a construírem suas identidades docentes e seu protagonismo diante dos desafios e das possibilidades do contexto da EFA.

Palavras-chave: Identidade docente. Educação do campo. Pedagogia da alternância.

\section{ABSTRACT}

The article aims to present some thoughts about the educational practices of educators from the Escola Família Agrícola - EFA (Agricultural Family School) "Zé de Deus", located at Colinas do Tocantins, in the state of Tocantins (TO). The methodological path adopted in this qualitative research was oral history, with life narratives from six teachers. As a result, we identified that, in order to teach at EFA, it was necessary to deal with new schooling proposals and with teaching methodologies that were more appropriate to the rural context. The teachers narrated that, when they came into contact with the reality of the EFA "Zé de Deus", they learned about the importance of dialogical education, as a basis for Alternating Pedagogy, as well as to build their teaching identities and their role in face of the challenges and possibilities of the EFA context.

Keywords: Teacher identity. Rural education. Pedagogy of alternating.

\footnotetext{
${ }^{1}$ Esta pesquisa foi realizada de acordo com o parecer de aprovação do Comitê de Ética do Hospital de Doenças Tropicais da Universidade Federal do Tocantins (HDT/Araguaína), processo número 2.919.197, aprovado em 26 de setembro de 2018. Trata-se de resultados de pesquisa obtidos durante o Mestrado Interdisciplinar em Estudos de Cultura e Território.

${ }^{2}$ Mestre em Estudos Interdisciplinares de Cultura e Territónio pela Universidade Federal do Tocantins, Graduação em Letras pela Universidade Federal do Tocantins. Secretária Executiva na Universidade Federal do Tocantins - Câmpus de Araguaína. E-mail: alinnezinh@hotmail.com. alinne01@uft.edu.br.

${ }^{3}$ Doutora em Educação pela Universidade de São Paulo (USP). Mestre em Educação Universidade Estadual de Campinas (Unicamp). Pedagoga. Professora Adjunta do Curso de Licenciatura em História da Universidade Federal do Tocantins (UFT). Docente do Programa de Pós-Graduação em Estudos de Cultura e Território (UFT). E-mail: rosaria@uft.edu.br.

${ }^{4}$ Doutora em Sociologia pela Universidade Federal de Goiás, Mestra em Educação pela Universidade Federal de Goiás, Especialista em educação e agroecologia pela Universidade Estadual de Goiás, Graduada em História pela Universidade Federal de Pemambuco. Docente do Ensino Superior do Departamento de Educação do Campo- Artes e Música, Vice-coordenadora e docente do Programa de pósgraduação em Estudos de Cultura e Território (PPGCult) da Universidade Federal do Tocantins, Integra o coletivo de pesquisadores do Sub/7/Rede Universitas-Brasil. Integra a equipe de pesquisadora do Projeto Nova Cartografia Social da Amazônia (PNCSA). Compõe o coletivo de pesquisadores da Universidade Nacional de Santiago Del Estero (UNSE), no Instituto de Desenvolvimento Social, (INDES), Santiago Del Estero-Argentina. Membra da IGS GRAMSCI Brasil. E-mail: rejmedeiros@uft.edu.br.
} 


\section{INTRODUÇÃO}

Como prática da liberdade, dialogamos com Freire (2011), ao defender a educação como ato político, e na sua base revolucionária, em busca da construção de uma sociedade mais justa. Concordamos, também com a ação cultural para a libertação, cuja denúncia se faz na perspectiva de uma realidade desumanizante e o anúncio decorre do compromisso histórico com homens e mulheres, em busca de sua dignidade e humanização.

Noutra passagem, Freire (2011) adverte que não existe uma prática educativa neutra, sem compromissos políticos. Por isso, se constitui em "[...] práxis, porém, é reflexão e ação dos homens sobre o mundo para transformá-lo. Sem ela, é impossível a superação da contradição opressor-oprimido" (FREIRE, 2011, p. 38). Logo, a partir desses fundamentos, apresentamos a compreensão sobre a educação do campo, enquanto prática de emancipação humana. Para contribuir com nossas reflexões Fernandes, Cerioli e Caldart (2009, p. 25) definem a expressão educação do campo:

[...] Decidimos utilizar a expressão campo e não mais usual meio rural, com o objetivo de incluir no processo da Conferência uma reflexão sobre o sentido atual do trabalho camponês e das lutas sobre o sentido atual do trabalho camponês e das lutas sociais e culturais dos grupos que hoje tentam garantir a sobrevivência deste trabalho. Mas quando discutimos a educação do campo estamos tratando da educação que se volta ao conjunto dos trabalhadores e das trabalhadoras do campo, sejam os camponeses [...].

A partir dessas prerrogativas, os autores supracitados nos apresentam a educação do campo como uma matriz que "constrói referências culturais e políticas para a intervenção das pessoas e dos sujeitos sociais na realidade, visando a uma humanidade mais plena" (FERNANDES; CERIOLI; CALDART, 2009, p. 23).

Ainda sobre as definições de educação do campo, Caldart (2009, p. 38) chama atenção para a chave metodológica de estudos da matriz de educação campo:

[...] A educação do campo se coloca em luta pelo acesso dos trabalhadores ao conhecimento produzido na sociedade e ao mesmo tempo problematiza, faz crítica ao modo de conhecimento dominante e à hierarquização epistemológica própria desta sociedade que deslegitima os protagonistas originários da educação do campo como produtores de conhecimento e que resiste a construir referências próprias para solução de problemas de uma outra lógica de produção e de trabalho que não seja a do trabalho produtivo do capital.

Dessa forma, trataremos do lócus desta pesquisa, a Escola Família Agrícola (EFA) "Zé de Deus", um espaço de ensino voltado ao atendimento da população do campo, próxima à cidade de Colinas do Tocantins. Inserida nesse contexto, essa EFA nasceu com o objetivo de educar as/os filhas/os de agricultoras/es e demais pessoas que moram no campo, ampliando suas perspectivas de permanência em suas comunidades rurais. As EFAs adotam pedagogias que respeitam os modos de vida dessa população, mas que também possibilitam mobilizar nesses jovens uma consciência de mundo, para que possam ter suas identidades fortalecidas e continuar aprimorando os conhecimentos, construídos na EFA, em práticas culturais, sociais, econômicas e políticas, desenvolvidas em seus contextos de vida. 
Por meio de entrevistas 5 com as/os educadoras/es da EFA "Zé de Deus", estruturadas pelos princípios da História oral, identificamos a pedagogia da alternância, baseada na especificidade da cultura camponesa, que tem como referência curricular a associação da prática e da teoria no processo de ensino/aprendizagem de forma a estabelecer um diálogo com a vida das/os alunas/os; e os conteúdos curriculares do ensino médio. Em outras palavras, há uma organização didática que busca relacionar o cotidiano das/os camponesas/es e a parte teórica do currículo formal, viabilizando a aproximação da realidade com os contextos dos estudantes.

A pedagogia da alternância busca, sobretudo, integrar dois espaços e tempos, entendendo que há saberes diferentes que se completam e que há aprendizagens fora do ambiente escolar que são fundamentais para o enriquecimento da proposta pedagógica da EFA. Portanto, também há na construção do ser educador/a certa alternância em se fazer docente na prática. Alternância entre os espaços e lugares formadores; entre passado, presente e futuro, bem como entre "culturas" partilhadas no mesmo tempo e espaço.

Com o objetivo de considerar essas subjetividades, a História oral e as narrativas de vida das/os docentes nos apresentaram contribuições metodológicas importantes para o desenvolvimento desta pesquisa. Para Alberti (2005), "a História oral é um caminho interessante para se conhecer, registrar múltiplas possibilidades que se manifestam e dão sentido a formas de vida e escolhas de diferentes grupos sociais, em todas as camadas da sociedade". Assim, caracterizamos esta investigação como qualitativa, pois, a partir de observações e entrevistas com as/os docentes da EFA (Quadro 1), sistematizamos os conhecimentos construídos nas e pelas suas histórias de vidas.

Quadro 1 - Perfil dos interlocutores ${ }^{6}$

\begin{tabular}{|l|l|c|}
\hline Professores (idade) & \multicolumn{1}{|c|}{ Formação } & $\begin{array}{c}\text { Tempo de atuação } \\
\text { na EFA "Zé de Deus }\end{array}$ \\
\hline $\begin{array}{l}\text { Césio Silva Pinho } \\
\text { (37 anos) }\end{array}$ & $\begin{array}{l}\text { Técnico em Agropecuária e especialização em } \\
\text { "Saberes da Terra"7 }\end{array}$ & 13 anos \\
\hline $\begin{array}{l}\text { Kelson Fiuca de Souza } \\
\text { (33 anos) }\end{array}$ & $\begin{array}{l}\text { Engenheiro Agrônomo e Especialista em } \\
\text { Georeferenciamento de imóveis rurais e urbanos }\end{array}$ & 9 anos \\
\hline $\begin{array}{l}\text { Evane Gentil dos Santos } \\
\text { Barreto (42 anos) }\end{array}$ & Engenheiro Agrônomo e técnico em magistério & 4 anos \\
\hline $\begin{array}{l}\text { Pedro Alves Chaves } \\
\text { (53 anos) }\end{array}$ & $\begin{array}{l}\text { Magistério (nível médio) Letras, Língua Portuguesa e } \\
\text { Língua Inglesa }\end{array}$ & 1 ano \\
\hline $\begin{array}{l}\text { Cirlene Rodrigues da Silva } \\
\text { (39 anos) }\end{array}$ & $\begin{array}{l}\text { Curso Técnico em Enfermagem/Licenciatura em } \\
\text { História e Especialista em Psicopedagogia }\end{array}$ \\
\hline $\begin{array}{l}\text { Dayanne Alves Abreu } \\
\text { (29 anos) }\end{array}$ & $\begin{array}{l}\text { Licenciatura em Ciências Naturais com habilitação } \\
\text { em Física e especialista em Física Geral e Aplicada }\end{array}$ & 1 ano \\
\hline
\end{tabular}
Fonte: Dados da pesquisa (2018).

Para Sánches Gamboa (2003, p. 394), o método qualitativo "prima pela compreensão dos fenômenos nas suas especificidades históricas e pela interpretação intersubjetiva dos eventos e acontecimentos". Logo, para compreendermos a construção da identidade desses professores, corroboramos com esse autor, ao afirmar que: "[...] a pesquisa começa com a localização dos problemas. Com base nas situações-problema

\footnotetext{
${ }^{5} \mathrm{O}$ entrevistador deverá colocar-se na postura de parteiro de lembranças, facilitador do processo que se cria de resgatar as marcas deixadas pelo passado na memória (MONTENEGRO, 2003, p. 150).

${ }^{6}$ Os participantes concordaram com a divulgação de seus nomes na publicação dos resultados desta pesquisa.

${ }^{7}$ No ano de 2014 ocorreu o Curso de Aperfeiçoamento em Educação do Campo, Agricultura Familiar e Envolvimento Social no Tocantins promovido pelo Programa Projovem Campo, Saberes da Terra e Universidade Federal do Tocantins (UFT).
} 
se explicitam as dúvidas, as suspeitas, as indagações e as questões. Essas questões devem ser qualificadas até serem transformadas em perguntas, claras e concretas" (SÁNCHES GAMBOA, 2003, p. 397).

Ainda em relação a metodologia, nas próximas três seções, destacaremos que para se lecionar em uma EFA é necessário lidar com novas propostas escolares e com metodologias de ensino mais adequadas ao contexto campesino. Os seis professores narraram que, ao entrarem em contato com a realidade da EFA "Zé de Deus", aprenderam sobre a importância da educação dialógica, como base na pedagogia da alternância; a construírem suas identidades docentes e seu protagonismo diante dos desafios e das possibilidades do contexto da EFA.

\section{EducAÇÃo dialógicA NA EFA "ZÉ DE DEUS": BASE PARA UMA PEDAGOGIA dA ALTERNÂNCIA}

A obra pedagogia do oprimido se insere no movimento de educação e cultura popular, enquanto experiências desenvolvidas nos anos de 1950 e 1960 no Brasil. Os contextos dessas experiências marcaram um esgotamento do populismo e ocorreram por meio de grandes manifestações populares, que revelaram a afirmação dos movimentos sociais como respostas às políticas governamentais da época.

Segundo Arroyo (2012, p. 555), "o movimento de educação e cultura popular significa uma resposta político-pedagógica a essas tensões, que não se limitam ao Brasil, mas estão expostas nos povos da América Latina e nos povos da África, em reação contra o colonialismo". O autor faz uma advertência sobre o sentido que Freire desenvolveu na "Pedagogia do Oprimido", pois nada tem em promover uma educação para os excluídos e sim, pauta-se na história vivenciada, esperançada pelos grupos sociais que lutam, como forma de resistência, em busca de melhores condições de vida, educação, saúde, trabalho, políticas públicas, enfim, lutam por uma sociedade que aporte transformações e, por conseguinte, para que haja a emancipação de homens e mulheres. Em relação ao conceito-concepção dessa obra freireana.

[...] A Pedagogia do Oprimido nos ensina que enquanto as experiências sociais, humanas, de trabalho, das vivências e resistências não forem reconhecidas e explicitadas como conformantes dos conceitos, das teorias e dos valores, não encontrarão significados históricos, não terão força pedagógica, nem política. (ARROYO, 2012, p. 554).

Dessa forma, a matriz formadora da concepção de educação em Freire (2011), além de pautar-se no trabalho, como princípio educativo, apresenta reflexões sobre a vivência e a condição do oprimido de libertar-se da opressão e também de recuperar a humanidade dos opressores. A partir desses pressupostos teóricos sobre educação, trazemos a pedagogia da alternância, enquanto síntese cultural, cuja matriz pedagógica é desenvolvida na EFA "Zé de Deus". Salientamos que a pedagogia da alternância está em construção permanente, sendo delineada através de práticas educativas próprias de seu contexto, ou seja, um trabalho dinâmico sustentado pelo tripé família, escola e comunidade.

A pedagogia da alternância não se configura somente pela relação teoria e prática. É, sobretudo, um sistema educativo que se caracteriza por um projeto político-pedagógico com finalidades de formação integral; uma visão do educando como sujeito de sua formação; uma rede de parcerias entre família, e coletivo de educadores da escola; um 
dispositivo pedagógico enquanto instrumento didático e, uma concepção de educador como mediador dos processos pedagógicos (ROCHA-ANTUNES; MARTINS, 2012).

Nesse sentido, apresentamos as perspectivas das/os educadores da EFA em relação à escola, aos discentes e à dinâmica escolar proposta pela pedagogia da alternância. Esta vem ao encontro do atendimento ao direito de estudar e trabalhar das/os filhas/os de agricultoras/es, camponesas/es e sujeitos do campo em geral, preservando seus modos de vida e suas culturas. Esse modelo pedagógico contribuiu para que a EFA "Zé de Deus" não representasse apenas um lugar de produção de conhecimento, mas também um lugar que gera afetividade por parte dos docentes entrevistados.

[...] A Pedagogia da Alternância atribui grande importância à articulação entre momentos de atividade no meio socioprofissional do jovem e momentos de atividade escolar propriamente dita, nos quais se focaliza o conhecimento acumulado, considerando sempre as experiências concretas dos educandos. (TEIXEIRA; BERNARTT; TRINDADE, 2008, p. 229).

Assim, a proximidade com as/os educandas/os, a responsabilidade em colaborar com o processo de mudança de perspectivas dos estudantes, oriundos de uma parcela marginalizada da sociedade, possibilitam essas/es profissionais a se construírem de uma forma mais sensível ao lugar que estas/es estudantes ocupam na sociedade. Freire (2011) enfatiza a necessidade de uma educação pelo diálogo entre educadoras/es e educandas/os:

[...] Na medida em que os homens, simultaneamente refletindo sobre si e sobre o mundo, vão aumentando o campo de sua percepção, vão também dirigindo sua "mirada" a "percebidos" que, até então, ainda que presentes ao que Husserl chama de "visões de fundo", não se destacavam, "não estavam postos por si". Desta forma, nas suas "visões de fundo", vão destacando percebidos e voltando sua reflexão sobre eles. (FREIRE, 2011, p. 99).

Na EFA "Zé de Deus", ao alternar o tempo escola e o tempo comunidade, há essa necessidade de reflexão/ação sobre a vivência de mundo do aluno e o ensino recebido na escola, isto é, o professor é a ponte entre a ação e a reflexão dos jovens, colaborando para sua formação crítica e consciente. Assim, Caldart (2009, p. 110) destaca alguns elementos da escola do campo:

[...] Uma escola do campo não é, afinal, um tipo diferente de escola, mas sim é a escola reconhecendo e ajudando a fortalecer os povos do campo como sujeitos sociais, que também podem ajudar no processo de humanização do conjunto da sociedade, com suas lutas, sua história, seu trabalho, seus saberes, sua cultura, seu jeito. Também pelos desafios da sua relação com o conjunto da sociedade. Se for assim, ajudar a construir escolas do campo como sujeitos organizados em movimento. Porque não há escolas do campo sem a formação dos sujeitos sociais do campo, que assumem a luta por esta identidade e por um projeto de futuro.

A EFA "Zé de Deus" está inserida na busca de atender o jovem que reside no campo, em torno da cidade de Colinas do Tocantins, em regime de alternância entendendo que o curso Técnico em Agropecuária integrado ao Ensino Médio representa "uma oportunidade de profissionalização para os filhas/os de trabalhadoras/es do campo, que Ihes permitirão continuar lidando com a terra, melhorando as técnicas de produção e sublimando as estatísticas relativas ao êxodo rural" (TOCANTINS, 2017, p. 4). 
Sobre a modalidade pedagógica em alternância, os autores Cordeiro, Reis e Hage (2011, p. 116) destacam que:

[...] Assumindo o trabalho como princípio educativo, a Pedagogia da Alternância permite aos jovens do campo a possibilidade de continuar os estudos e de ter acesso aos conhecimentos científicos e tecnológicos não como algo dado por outrem, mas como conhecimentos conquistados e construídos a partir da problematização de sua realidade, que passa pela pesquisa, pelo olhar distanciado do pesquisador sobre o seu cotidiano.

$\mathrm{Na}$ concepção de escola do campo é fundamental que o profissional se identifique com sua profissão e com a pedagogia da alternância, refletindo sobre seu processo de formação, a partir das experiências, em busca de melhorar suas práticas educativas no contexto campesino. Assim, a/o educadora/o poderá conhecer novos saberes, consequentemente, a afirmação de uma identidade que contribuirá bastante para sua atuação profissional.

As características mais presentes da pedagogia da alternância na EFA "Zé de Deus" é o regime de funcionamento de semi-internato e, segundo o Plano de curso da EFA:

[...] O Ensino Médio Integrado ao Técnico em Agropecuária da Escola Família Agrícola Zé de Deus de Colinas do Tocantins está organizado em seis áreas do conhecimento. São elas: Planejamento e Projeto, Produção Vegetal e Produção Animal, Produção Agroindustrial, Gestão e Estudos Ambientais, e Práticas e Estágio. A carga horária total é de 5.310 horas aulas, operacionalizadas mediante calendário e cronogramas flexíveis de maneira que possibilite ao aluno acompanhar o ciclo produtivo de determinada cultura ou da pecuária em diferentes tempos e lugares. Com o auxílio dos instrumentos pedagógicos próprios da Pedagogia da Alternância, podendo alguns critérios ser adotada pela escola, aliado ao desenvolvimento das cinco áreas básicas do conhecimento, compreende-se que o "aprender a aprender" defendido pela UNESCO torna-se cada vez mais possível para a população camponesa. (TOCANTINS, 2017, p. 10).

Diante disso, as/os docentes e discentes da EFA "Zé de Deus" mobilizam seus saberes, a partir dos seguintes instrumentos (TOCANTINS, 2017):

Plano de Estudo (PE) - Constitui o principal instrumento metodológico. É um método de pesquisa participativa, por meio de um questionário; possibilita analisar os vários aspectos da realidade do estudante, promove uma relação autêntica entre a vida e a escola.

Projeto pessoal do jovem (PPJ) - trata-se de um projeto profissional que o jovem irá buscar desenvolver em sua propriedade. É desenvolvido e orientado por um professor e ao final do curso esse projeto será defendido pelo estudante, semelhante à defesa de um Trabalho de Conclusão do Curso (TCC).

Colocação em Comum - A avaliação de habilidade/convivência acontece preferencialmente a cada semestre. Através de um roteiro subsidiado por um tema, 0 estudante faz (auto)avaliação, a família o avalia e um colega de classe também faz a avaliação do estudante, e na escola é feita a colocação em comum com a turma fazendo as devidas reflexões.

Caderno da Realidade - Registro de conhecimentos sobre a realidade mais próxima da vivência do estudante.

Coordenadores da Semana - Há uma votação que escolhe dois alunos para coordenar as equipes de limpeza e organização da escola durante a semana. As equipes lavam as panelas do almoço, cuidam dos jardins e cuidam dos dormitórios masculino e feminino.

Observadas às orientações da pedagogia da alternância, a escola busca proporcionar a/o jovem do campo, além das disciplinas comuns à rede regular de ensino, um projeto de vida e de potencialidade para promover a formação para uma conscientização coletiva. Os instrumentos citados acima, além de organizarem os períodos de 
aprendizagem, são a garantia da relação que deve ser bem próxima entre, a escola, a comunidade e a família, condição essencial para uma educação familiar agrícola.

Nesse sentido, diante da necessidade de fortalecimento dos sujeitos do campo, por meio da educação, temos o excerto da entrevista do professor Souza (2018), no qual percebemos que na EFA "Zé de Deus" existe uma preocupação com o sucesso do educando, o que envolve também a identidade do professor, pois este se vê diante da adoção de uma nova postura profissional para conseguir resultados com os alunos.

Aqui há sim uma preocupação com o aluno se ele vai aprender ou não. Eu já pensei sim de dá uma aula para aqueles alunos que tem menos interesse e se eles quiserem bem, mas não tem como, porque o contato é muito grande é eu me tornei mais sensível assim, porque eu procuro vero porquê que aquele aluno está mais desinteressado, ver a fonte se há algum problema familiar. Então, aqui na EFA tem isso. (SOUZA, 2018, n.p.).

Por meio das narrativas, observamos que as identidades docentes e pessoais ganharam novas configurações e, no processo, podemos notar que a afetividade em relação ao "lugar" e aos indivíduos com que entraram em contato consiste em ponto de convergência entre todos as/os professoras/es entrevistadas/os, como fica nítido nos relatos de Abreu (2019) e Silva (2018):

Lá na EFA enquanto os alunos estiverem lá no pátio é para está lá todo mundo junto, então você começa um nível de intimidade melhor com os alunos e isso principalmente para mim que sou das exatas Física, Matemática e Química. O caso é que às vezes eles não gostam da matéria, aí eles começam a gostar da professora e depois gostam da disciplina. Todos começam a se identificar com a matéria depois que começam a gostar da professora. Se o aluno não gostar de mim, de jeito nenhum, eu não consigo trabalhar com as exatas. Então, esse tempo de convivência ajuda isso faz você mudar em sala de aula, você cria uma intimidade maior com os alunos. (ABREU, 2019, n.p.).

Esse ano uma aluna da terceira série veio me dizer assim: "professora como eu cresci eu já consigo comparar uma coisa com a outra". Eu falei: Parabéns era isso que eu queria! Ela disse que quando alguém fala algo ela vai atrás verificar se está falando a verdade para ver se posso discordar, é assim, é um trabalho de formiguinha, se um ou outro conseguir captar já vale a pena.[...] Eu acho [...] que é você vestir a camisa e conhecer a realidade de aluno por aluno, aqui tem alunos com realidades muito diferentes, se eu for analisar o aluno pela série que ele está não vai, não trabalho.(SILVA, 2018, n.p.).

Nos trechos das narrativas dos professores Souza, Abreu e Silva podemos observar que as identidades docentes são modificadas de acordo com o perfil de alunos que recebem na EFA e que o contato que estabelecem com eles os fazem buscar mecanismos para ficarem mais próximos das necessidades dos educandos, o que favorece a aprendizagem dos conteúdos. A esse respeito Freire (2018, p.57-58) nos direciona a pensar que:

[...] O ideal é que, na experiência educativa, educandos, educadoras e educadores, juntos, 'convivam' de tal maneira com este como com os outros saberes de que falarei que eles vão virando sabedoria. Algo que não nos é estranho a educadoras e educadores. [...] O respeito à autonomia e à dignidade de cada um é imperativo ético e não um favor que podemos ou não conceder uns aos outros.

Ainda na obra "Pedagogia do Oprimido", Freire (2011) faz uma necessária discussão sobre o ser humano e sua busca de "ser mais"; da necessidade ontológica de seres críticos e conscientes e, a partir disso, transformadores da realidade. Freire (2011) entende que existe em nossa sociedade uma cultura de opressão predominante e que 
uma mudança de percepção de mundo pelo oprimido pode mudar essa situação, o que pode acontecer a partir da "síntese cultural".

Esse conceito é uma das características do que Freire (2011) denominou como "teoria da ação dialógica", que visa a superação das contradições entre opressores e oprimidos pelo diálogo entre culturas, sendo que uma cultura não menospreze a outra. No caso da EFA "Zé de Deus", o fato de as/os docentes não chegarem com a imposição de conteúdos e de formas de pensar dominantes, já os aproxima de ações dialógicas.

Agir pelo diálogo e, pela colaboração são exemplos de que há na EFA uma busca pela associação de saberes, que contribui para um ensino pautado no diálogo e na síntese de culturas que, de acordo com Freire (2011, p. 249), "não nega as diferenças entre uma visão e outra, pelo contrário, se funda nelas. O que ela nega é a invasão ${ }^{8}$ de uma pela outra. O que ela afirma é o indiscutível subsídio que uma dá a outra". Vejamos a narrativa do Professor Barreto sobre esses subsídios:

Hoje ouvindo o aluno que eu estava orientando, ele fez no PPJ [Projeto pessoal do jovem] dele uma experiência que serviu para mim. A experiência dele foi plantar o feijão com 0 adubo químico e com o esterco de gado. Segundo ele, o esterco estava disponível lá, no vizinho e de graça. Segundo ele, a produtividade do feijão foi a mesma. Aí essa eu vi que deu certo, mas eu vou plantar lá em casa, ver e depois vou trazer para explicar em sala de aula com os alunos. Ali é um exemplo, que já serviu para mim! (BARRETO, 2018, n.p.).

A base da educação problematizadora de Freire (2011) é o diálogo, em que o/a educador/a não se reconhece como autoritário e detentor de todo o "saber", mas um profissional da educação com autoridade, seguro do equilíbrio necessário no contexto pedagógico, fundamentado na síntese de culturas e de ideias entre educandas/os, como vemos na narrativa de Souza:

\begin{abstract}
Falar a mesma língua. Que os alunos devem ter o conhecimento técnico aqui, mas quando for transmitir falar a mesma língua. Em termos de materiais, de estrutura, a gente também valoriza muito! Eu particularmente valorizo muito fazendo as visitas nas propriedades dos alunos, conhecer, dar importância e valorizar isso, através dessas visitas. Independente de onde seja, de como é a produtividade daquele local, tentamos valorizar cada vez mais para que os alunos também valorizem. (SOUZA, 2018, n.p.).
\end{abstract}

Nas narrativas acima, evidenciamos que os docentes Barreto e Souza têm buscado valorizar os saberes trazidos pelas/os educandas/os, a partir do contexto que vivem suas famílias. Em outras palavras, entendemos como um passo importante para a "síntese cultural", pois o professor ao se colocar na condição de aprender é uma atitude que demonstra que não existe uma cultura soberana, que as culturas são mistas e uma depende da outra para sobreviver em sociedade.

\title{
CONSTRUÇões dAS IDENTIDADES DE EduCADORAS/ES NA EFA “ZÉ DE DEUS”
}

Ao tratarmos das reflexões sobre práticas educativas, destacamos anteriormente sobre a formação integral e emancipatória das/dos educandas/os e a elaboração de síntese cultural, a partir de práticas educativas, baseadas na pedagogia da alternância enquanto

\footnotetext{
8 Segundo Paulo Freire (2011, p. 205), a "invasão cultural", é uma modalidade da ação antidialógica e consiste na penetração cultural que os invasores fazem no contexto dos invadidos.
} 
movimento de formação integral e emancipatória dos sujeitos envolvidos no processo de ensino e aprendizagem.

É importante lembrar que a interação educativa entre escola, comunidade e família é um requisito fundamental para o sucesso na aprendizagem dos estudantes. No que diz respeito aos educandos da EFA, a professora Abreu (2019) também enfatiza que há necessidade de uma presença maior dos familiares.

[...] Então, nem sempre a família deles está presente. Mas, lá na EFA temos alunos que tem 17 anos e, já toma de conta da vida dele, ele quem sabe o que ele quer porque nem sempre tem os pais presentes. Mas a EFA é mais acolhedora para os alunos e eles chegam lá na EFA tristes, muito tristes. Eles chegam falando assim: Tia (ou professora) nunca vi isso! [...]. Ai você se depara com alunos que pensam em desistir, ai você vai se aproximando, desenvolvendo o conteúdo. Porque tem alunos nossos que trabalham e trabalham muito, aquela semana que eles vão para casa eles trabalham, até mesmo para pagar o transporte e vir para a escola para estudar.

A narrativa acima nos mostra que o profissional que atua na EFA "Zé de Deus", por vezes, precisa assumir outras identidades além de a de professor/a, mas também de amiga/o ou conselheiro para conseguir se aproximar das/os alunas/os que chegam bastante tímidos e com dificuldades de aprendizagens, ou seja, a construção desse laço afetivo é fundamental para que eles consigam permanecer na escola e ter um bom rendimento nos estudos.

Nesse movimento de análise em relação à identidade e ao contexto, Hall (2006, p. 12) enfatiza que a "identidade costura [...] o sujeito à estrutura. Estabiliza tanto os sujeitos quanto os mundos culturais que eles habitam, tornando ambos reciprocamente mais unificados e previsíveis". Acreditamos que, a partir do instante que o/a professor/a se identifica com a dinâmica de funcionamento da EFA, se sente mais pertencente à cultura da escola, reconhecendo a importância da presença das famílias na escola para contribuir com seu trabalho de formação do discente.

Morando em Colinas desde seu nascimento, o docente Pinho (2018) se considera um profissional que busca qualificar a formação das/os educanas/os da EFA. Destacando que, "[...] para se tomarem profissionais com questões morais e éticas, humildade, é preciso ser bons profissionais, saberem lidar com pessoas". Ao trabalhar a/o discente para que tenham os valores mencionados acima, percebemos que o elo entre a pessoa e o profissional é tênue, ao passo que nessa fala externam as características pessoais e o desejo profissional de provocar a mudança em alguns/as educandos que "[...] chegam à EFA sem querer aprender e saem pessoas transformadas e as próprias famílias reconhecem essa mudança [...]'.

Compreendemos que ao construir sua identidade docente na EFA "Zé de Deus", o ser educador para Pinho (2018) tem se realizado pela "seriedade e decência" (FREIRE, 2018), em práticas preocupadas com a humanização da/o educanda/o. Além disso, busca estabelecer com o contexto escolar uma relação de pertencimento com a escola família agrícola, ou seja, fica evidente, na última narrativa citada acima, que o educador valoriza o seu lugar de atuação, sentindo-se comprometido com a EFA. Identificar-se, reconhecer-se como educador leva tempo; um tempo para construir essas imagens, falamos no plural porque a carreira docente é permeada por imagens que o/a educador/a tem de si mesmo, como também da imagem feita por outras/os pessoas.

Arroyo (2010, p.13) corrobora com a ideia que "[...] o que sabemos fazer e temos de fazer, no cotidiano do convívio com a infância, adolescência e juventude não cabe em 
imagens simplificadas, nem em um único conceito, professor, docente, mestre, alfabetizador, supervisor, orientador [...]". Segundo o autor, carregamos diversas imagens que são construídas dentro de nossas histórias e que muitas vezes carregam traços comuns ao ofício. Logo, analisando as narrativas de Pinho (2018), observamos o ser educador como uma imagem elaborada por ele e vista pela sociedade; esta imagem, assim como sua identidade se faz e se refaz nas relações humanas que ele participou durante sua trajetória de vida.

Freire (2018) ressalta que somos "seres inacabados" e que ao percebermos essa condição de seres inconclusos, agimos e nos confrontamos com as situações que a vida nos apresenta e, no tocante a vida de professor essa inconclusão leva-o a construção do ser e estar na profissão:

[...] O melhor ponto de partida para estas reflexões é a inconclusão do ser humano de que se tornou consciente. Como vimos, aí radica a nossa educabilidade, bem como a nossa inserção num permanente movimento de busca em que, curiosos e indagadores, não apenas nos damos conta das coisas, mas também delas podemos ter um conhecimento cabal. A capacidade de aprender, não apenas para nos adaptar, mas sobretudo para transformar a realidade, para nela intervir, recriando-a, fala de nossa educabilidade a um nível distinto do nível do adestramento dos outros animais ou do cultivo das plantas". (FREIRE, 2018, p. 67).

Somos, portanto, seres que buscam a mudança e o crescimento independente de nossa função e, sendo educadoras/es ao buscar os aprendizados da prática e ao refletir sobre nossa prática, estamos, sobretudo, dialogando com a realidade dos educandos e recriando a nossa própria realidade. Sobre isso, o professor Chaves percebe que há peculiaridades em relação aos educandos que chegam à EFA "Zé de Deus":

Agora o nível de estudo daqui é diferente, porque a gente pega uma clientela de diversos municípios, de diversas camadas sociais, principalmente aqueles que vêm de assentamentos e de origem rural e vêm para dentro de uma escola feito a nossa. E daqui ele tem uma formação técnica e sai daqui apto a prestar o serviço técnico agrícola para outras instituições, nós temos alunados que saíram daqui e já estão trabalhando no Ruraltins. Dos 23 que se formaram o ano passado, oito estão na faculdade, então, isso é visível que o ensino aqui é bom, tem qualidade e dá resultados (CHAVES, 2018, n.p.).

Analisando essa narrativa de Chaves (2018), a Escola Família Agrícola "Zé de Deus" tem contribuído para a melhoria do ensino da região, pelo seu potencial transformador da vida das/os educandas/os a partir da vivência na EFA. Freire (2011) entende que o professor consciente de sua função e sabendo-se sujeito da transformação não pode estar no mundo de forma neutra, ele deve buscar uma educação problematizadora, que possibilite ao educando aprender de forma simultânea com o mundo a sua volta. De acordo com Freire (2011, p. 55) “[...] num pensar dialético, ação e mundo, mundo e ação, estão intimamente solidários. Mas a ação só é humana quando, mais que um puro fazer, é quefazer, isto é, quando também não se dicotomiza da reflexão [...]".

\section{EFA “ZÉ DE DEUS": PROTAGONISMOS DE EDUCADORAS/ES E EDUCANDAS/OS NA CONSTRUÇÃO DE EDUCAÇÃO DO/NO CAMPO, NO TOCANTINS}

Concordamos com Moita (2013, p. 136) ao afirmar que "[...] a profissão é um espaço de vida que é atravessado por processos de formação que, aparentemente, nada tem a ver com o mundo intraprofissional [...]". Nesse sentido, compreendemos que a formação de um professor é cotidiana, isto é, a maneira como abordará a realidade e os conteúdos, 
fazem parte da construção de seu modo de ser professor, o que passa a constituir vertentes de suas identidades.

Contribuindo para esse debate Paulo Freire (2018) destaca que os saberes são indispensáveis na formação da identidade do educador. Isso implica em dizer que as experiências desenvolvidas ao longo da vida ocorrem na troca de saberes entre quem ensina e quem aprende. Nesse aspecto, define o autor, não há docentes sem discentes e ambos se explicam e se complementam no processo de construção do ensinar e aprender, pois, "[...] apesar das diferenças que os conotam, não se reduzem à condição de objeto um do outro. Quem ensina aprende ao ensinar alguma coisa a alguém [...]" (FREIRE, 2018, p. 25).

Baseados nesses pressupostos e como proposta reflexiva, Freire, continua chamando atenção sobre o processo de formação da identidade docente no qual salienta que quanto mais exerce sua capacidade de aprender, mais o/a educador/a desenvolve sua "curiosidade epistemológica". O diferencial dessas premissas é que a educação pode ser libertadora quando não perde sua capacidade de problematizar, e, sobretudo na medida em que: "[...] servindo à liberdade, se funda na criatividade e estimula a reflexão e a ação verdadeira dos homens sobre a realidade, [...] como seres que não podem autenticar-se fora da busca e da transformação criadora (FREIRE, 2011, p 72).

A educação contrária à libertadora pauta-se na educação bancária que é o depósito de conteúdos, de transmissão de valores e conhecimentos, para os que se encontram na condição de aprendizes e nunca de quem ensina.

Como parte do processo de construção docente, Abreu (2019) relatou que a primeira escola onde atuou disponibilizava seu conteúdo em apostilas para que todas/os as/os professoras/es as seguissem. A partir deste relato nos deparamos com um dos primeiros desafios apresentados pela educação tradicional: seu aspecto bancário, criticado por Paulo Freire (2018) por ser antagônico à educação libertadora. Afinal, para Freire (2018), a educação libertadora e, portanto efetiva, é aquela baseada no exemplo e na relação dialógica entre educador/a e educandas/os e não em fórmulas pré-fabricadas, em forma de apostilas que ofertam pouca autonomia ao/a professor/a. Logo, o contexto do primeiro contato de Abreu (2019) com a profissão docente foi diferente daquela com que se deparou ao iniciar sua atuação na EFA "Zé de Deus".

Antes a professora Abreu (2019) se via em uma escola particular, onde ela seguia as apostilas de conteúdos, dava suas aulas e retornava para casa. Atualmente, ela se vê em uma escola que enfatiza a importância do convívio com os estudantes, do contato familiar entre educadoras/es e educandas/os. Para, ela "[...] EFA é o lugar que eu me apaixonei! De todas as escolas que eu já trabalhei a EFA despertou uma paixão. [...] Então, assim eu vejo a EFA como uma família acolhedora" (ABREU, 2019, n.p.). Ao analisar essa narrativa, percebemos que a professora compreende que o formato da EFA favorece o acolhimento de educadoras/es e de educandas/os, o que contribui para interação de sua identidade docente com o espaço de atuação, oportunizando a sua atuação na EFA.

Ao contrário da educação bancária, dialogaremos com as contribuições de Freire (2011) com sua perspectiva sobre a "síntese cultural" que, para o autor, é parte do processo de uma educação dialógica, problematizadora. Consequentemente, ao respeitar o contexto de vida e a cultura das/os educandas/os, opõe-se à "invasão cultural" e propõe as/os educandas/os o uso da cultura como instrumento de libertação. Freire (2011, p. 247) define que "na síntese cultural os atores se integram com os homens do povo, atores 
também, da ação que ambos exercem sobre o mundo". Portanto, para que ocorra uma síntese de culturas é necessária a participação do/a educador/a e dos educandos, em união, para compreender o mundo, em sua complexidade e transformar as realidades. Entendemos que uma educação que forme cidadãos críticos, capazes de atuar sobre seu contexto; uma educação que busque sintetizar saberes e modos de vida distintos, só ocorrerá com a mediação de educadoras/es comprometidos com a transformação social.

Uma dimensão importante que apareceu nas narrativas das/os educadoras/es foi sobre os sentimentos e os sentidos de atuar na Escola Família Agrícola "Zé de Deus". Possibilitando um diálogo com o que Hall (2014, p.21), nos apresenta:

[...] Em parte, damos sentido às coisas pelo modo com as utilizamos ou as integramos em nossas práticas cotidianas. É o uso que fazemos de uma pilha de tijolos com argamassa que faz disso uma "casa"; e o que sentimos, pensamos ou dizemos a respeito dela é o que faz dessa "casa" um lar. Em outra parte ainda, nós concedemos sentidos as coisas pela maneira como as representamos - as palavras que usamos para nos referir a elas, as histórias que narramos a seu respeito, as imagens que delas criamos, as emoções que associamos a elas, as maneiras como as classificamos e conceituamos, enfim, os valores que nelas embutimos.

Sobre isso, quando perguntamos ao professor Pinho (2018) sobre os sentidos envolvidos em ser educador na EFA, ele destaca o seu compromisso em "dar o máximo que possibilite a formação dos alunos". Para ele, ser educador não é apenas ensinar conteúdos, ou seja, preocupar-se apenas com a dimensão técnica-profissional, mas formar "[...] um profissional que tenha a questão moral e ética e da humildade também, além de ser um bom profissional saber lidar com pessoas".

Assim, segundo Hall (2014, p.21), "[...] sentido é o que permite cultivar a noção de nossa própria identidade, de quem somos e a quem 'pertencemos' - e assim, ele se relaciona a questões de como a cultura é usada para restringir ou manter a identidade dentro do grupo [...]". Por isso, observa-se que, ao se preocupar com os valores éticos, Pinho (2018) revela a sua própria identificação com eles, isto é, constituindo-se parte da sua construção identitária docente na EFA "Zé de Deus".

A professora Abreu (2019) destaca a importância de incentivar as/os alunas/os da EFA a buscarem seu lugar no mundo e o sentido que ela atribui a sua prática é de uma educadora que entende e estimula que as/os educandas/os tornem-se protagonistas no mundo.

Sim, eu sempre falo para eles essa questão de ir atrás. Não se prendam só aqui no que eu falo para vocês, se eu ensinei uma coisa e você foi lá na sua casa e viu que tem uma coisa a mais, pesquise, procure e não só o assunto da minha disciplina mais do geral, eu sempre falo para eles que gosto que eles venham com coisas novas que nem eu estava sabendo. Ó professora aquilo que a senhora falou eu vi que tem mais isso e isso... É o que eu acho bacana. (ABREU, 2019, n.p.).

Enquanto que o professor Sousa (2018) reconhece que a dinâmica da EFA "Zé de Deus" é peculiar, pois "como o sistema aqui é de semi-internato mesmo, eles passam a semana aqui dormem aqui, manhã, tarde e noite, e o contato é maior". Ele congrega dos mesmos sentidos do ser educador/a narrados por Pinho (2018), ao afirmar características que passaram a compor sua identidade, a partir das experiências na EFA "Zé de Deus": "Eu sinto que eu sou mais carinhoso e não tem como não ser. O professor que vier para cá achando que irá dar sua aula, executar as atividades, dando aula e só passar o conteúdo 
para o aluno que quiser absorver ou não, esse professor está muito enganado [...]' (SOUZA, 2018, n.p.).

Professora Silva (2018) nos relata como a vivência com as/os educandas/os e a dinâmica da EFA "Zé de Deus" repercute na sua identidade; para ela a pessoa torna-se parte da escola, fazendo do local de trabalho a segunda casa, diante do modo como se dá o convívio na escola, o que para ela representa uma responsabilidade maior com as/os educandas/os.

É diferente aqui, nas outras escolas é possível separar o pessoal do profissional, mas aqui quando você começa a trabalhar no dia a dia se torna uma segunda casa e você nem tem tempo para respirar e pensar em nossos problemas, pensar nos alunos, porque temos alunos de várias realidades aqui. Aqui se você perguntar, alunos que têm familia e alunos que não têm, poucos vivem com a família tradicional, a maioria hoje vive só com a mãe, alunos criados pelos avós, ou pela madrasta. Aí você vê muita carência nos alunos que ficam aqui, aqueles que gostam, que se adaptam formam e se tornam alunos de casa e tem aqueles que não gostam e saem no primeiro ano porque eles querem voltar para outras escolas que não têm essas regras e querem estudar só um período. E nós somos professores responsáveis por esses alunos e cada um em sua função, somos responsáveis por eles (SILVA, 2018, n.p.).

Nesse sentido, as identidades docentes são resultados de vivências pessoais e profissionais, (re)construídas diariamente no convívio cotidiano com seus pares, considerando os sentidos sociais de ser educador/a na EFA "Zé de Deus". Para Hall (2006, p.12):

[...] O fato de que projetamos a 'nós próprios' nessas identidades culturais, ao mesmo tempo em que internalizamos seus significados e valores, tornando-os 'parte de nós', contribui para alinhar nossos sentimentos subjetivos com os lugares objetivos que ocupamos no mundo social e cultural.

Assim, as demandas da EFA "Zé de Deus" influenciam a percepção de quem as/os educadoras/es são para eles mesmos e para os outros, bem como o sentimento de pertença, articulado com os papéis sociais que ocupam, conforme aponta a narrativa do professor Chaves (2018):

Aqui na escola não, nós temos que fazer o papel completo se o aluno não quer [aprender] não, nós temos que motivá-los; levar para a sala de aula; levar para o campo; trazê-lo para a realidade para que ele possa amanhã ou depois, falar assim: "lá na EFA é diferente". (...) na EFA é diferente porque você fica com o aluno 24 horas, ai você acaba tendo de levá-lo ao hospital, suprir as necessidades dele, porque a escola só não supre $100 \%$ das necessidades do aluno; não supre o emocional, a parte de saúde, porque o aluno e professor são passivos disso, então, assim minha transformação foi muito notória, porque eu tinha outra visão de escola, outra visão de aluno. (CHAVES, 2018, n.p.).

Para a professora Silva (2018), o sentido de ser educadora na EFA está relacionado à dedicação, não só ministrar os conteúdos, mas também conhecer e compreender a realidades das/os educandas/os para que seja possível um aprendizado efetivo e contextualizado.

Você aqui tem muitos que se esforçam, que participam, principalmente nós professores de área temos esse objetivo de trabalho de formiguinha e os de agrárias é o de profissionalizar....] Eu aprendi muito aqui com isso!! Aqui eu tenho que analisar a realidade que $o$ aluno está vivendo, a pesquisar o aluno que você trabalha de onde ele veio e aí começar. O público que fundou a escola hoje não é mais o mesmo dos municípios que 
fundaram a escola, só Palmeirante que permanece, então tem que se resgatar essa ideologia da escola (SILVA, 2018, n.p.).

A nossa interlocutora Silva (2018) relatou ter aprendido bastante com sua atuação na EFA, obtendo crescimento pessoal e profissional, pois reconhece a importância de seu trabalho e o percebe como algo que, aos poucos, mostra os resultados. Esse conhecimento de si e da profissão é também um momento formador de identidade, pois a profissão se faz também na reflexão permanente sobre a prática docente. Nessa perspectiva, segundo Freire $(2018$, p. 40), "[...] por isso é que na formação permanente dos professores, o momento fundamental é o da reflexão crítica sobre a prática. É pensando criticamente a prática de hoje ou de ontem que se pode melhorar a próxima prática".

Nessa perspectiva, é que a educação do campo prevê princípios que valorizam a cultura das/os educandas/os, articulada à compreensão da economia e da sociedade como um todo, possibilitando que educando se torne um cidadão crítico e consciente do seu papel em sua comunidade. De acordo com o Plano de Curso da EFA "Zé de Deus":

[...] A educação baseada na Pedagogia da Alternância considera que a formação no meio rural, para ser completa depende das experiências vividas na escola, na família e na comunidade. Para tanto estabelece uma relação entre o meio em que vive o aluno e a EFA. Esse princípio educativo que concilia escola, vida e trabalho, consiste em repartir o tempo de formação do jovem em período de vivência na EFA e no meio, permitindo o desenvolvimento da vida pela reflexão. Esse ritmo alternado rege toda a estrutura da EFA, buscando a conciliação entre a escola e o fazer, permitindo que o jovem não se desligue da sua família e do seu meio (TOCANTINS, 2017, p. 10).

Assim, Schmitt (2017, p. 157) lembra que "a EFA surgiu como possibilidade de educação do campo, uma educação esperada pelas/os trabalhadoras/es rurais que se fixaram em assentamentos e em pequenas propriedades da região de Colinas do Tocantins". Por isso, as atividades desenvolvidas na EFA "Zé de Deus" são pautadas na educação do campo, cuja finalidade é de atender aos interesses dos povos do campo. Nesse sentido, há de se formar educadoras/es para "[...] "ajudar a construir e a fortalecer identidades; desenhar rostos, formar sujeitos, isto tem a ver com valores, modo de vida, memória, cultura" (MOLINA; JESUS, 2004, p. 26).

Esta também é uma das funções da escola: trabalhar com os processos de percepção e de formação de identidades, no duplo sentido de ajudar a construir a visão que a pessoa tem de si mesma (autoconsciência de quem é e com o que ou com quem se identifica), e de trabalhar os vínculos das pessoas com identidades coletivas, sociais: identidade de camponês, de trabalhador, de membro de uma comunidade, de participante de um movimento social, identidade de gênero, de cultura, de povo, de nação. (MOLINA; JESUS, 2004, p. 26).

Logo, é também papel da escola cultivar identidades, no sentido de contribuir para a percepção que a pessoa tem de si mesmo, do mundo a sua volta, do seu modo de vida e das diferenças existentes em nossa sociedade. Uma escola com a filosofia de escola do campo já nasce com essa perspectiva em torno de sua função de fortalecer vínculos identitários.

Durante as entrevistas, dentre outros fatores, ficaram evidentes os significados que as/os docentes atribuem às suas práticas pedagógicas. Assim, o que emergiram nas narrativas nos mostra pontos interessantes que merecem destaque: 
A gente observa o seguinte, que é gratificante ver o profissional que foi formado aqui exercendo uma função de técnico que ele passou por uma seleção, e que a questão foi 0 profissional e a pessoa que esse o amadurecimento da pessoa que teve uma boa formação, isso é o que a gente ouve falar de nossos alunos que estão atuando aqui.[...] Ele acaba entrando naquele mercado naquela comunidade como um aluno que está desenvolvendo o uma atividade e ali ele será um ponto de referência daquela atividade na região dele. Então, no trabalho e ele acaba sendo uma diferença e a gente trabalha esse profissional para lá na comunidade ele ser a referência [...] (PINHO, 2018, n.p.).

Em outra narrativa, a vida na universidade contribuiu para que Abreu (2019) mudasse sua maneira de pensar a educação, de ver que as/os educandas/os são diferentes e trazem realidades distintas que precisam ser educadas/os de formas diferentes, ao responder sobre os resultados das/dos educandas/os da EFA "Zé de Deus", a professora destacou seu sentimento:

Eu me sinto muito feliz muito orgulhosa e, eu falo isso para eles quando eu vejo um aluno que conseguiu. Quando você vê aquele aluno, aquele que tinha mais dificuldade, aquele que você insistia e não conseguia aprender e quando você vê o aluno passou, entrou na faculdade, conseguiu uma nota boa no ENEM. Então, é esforço deles e nosso como professor, tem que ter uma cooperação. (ABREU, 2019, n.p.).

A atitude da professora com suas/seus educandas/os revela a importância da capacidade da/o docente colocar-se em posição de ser humano que faz a diferença no mundo o que para Freire (2018, p. 20): "[...] Quer dizer, mais do que um ser no mundo, o ser humano se tornou uma presença no mundo, com o mundo e com os outros [...]".

A gente ouve o comentário que esse aluno saiu aqui da EFA e que foi indicado até por um de nós professores é gratificante né? Que este aluno está transmitindo e multiplicando esse conhecimento. [...] E eles dão continuidade de estar buscando o conhecimento mesmo depois da formação, a maioria da zona rural vem tirar alguma dúvida e isso para mim é muito gratificante, eles veem que o conhecimento é importante para mudar a situação. (SOUZA, 2018 , n.p.).

As narrativas acima deixam evidente a satisfação dos professores por contribuírem com o crescimento das/os educandas/os. Ao desempenharem esta função as/os educadoras/es assumem uma tarefa social na EFA que é oportunizar as/os educandas/os a desenvolverem uma consciência crítica em relação à sua realidade. Freire (2011, p. 49) destaca sobre o papel da educação libertadora que está baseada na reflexão e na ação:

[...] É preciso, enfatizemos que se entreguem a práxis libertadora. A prática libertadora só é possível a partir de uma educação que dialogue com o indivíduo, com o mundo a sua volta e que desenvolva neste o senso crítico. À medida que o homem tem consciência de si e se torna crítico, o sentimento de mudança brota nele.

Nesse sentido, o autor defende uma educação através do diálogo, no qual considera a/o educanda/o não como um recipiente vazio a ser preenchido, mas como sujeitos que possuem saberes diversos, e relevantes, no qual devem ser reconhecidos e valorizados pela escola. Nas narrativas acima, evidenciamos que as/os educadoras/es estão assumindo identidades docentes da escola do campo, visto que há uma preocupação quanto a formação de educandas/os, sobre o que é a emancipação das/os mesmas/os a partir dos conhecimentos construídos na EFA.

\section{CONSIDERAÇÕES FINAIS}


A dinamização do trabalho escolar na EFA, pautada pela pedagogia da alternância, destaca a relevância do/a educador/a como elo da cultura escolar com a construção de saberes que favoreçam a formação das/dos educandas/os do campo.

O que observamos nas falas das/os docentes da EFA "Zé de Deus" é que o caminho do diálogo está sendo percorrido e que todos têm consciência do seu inacabamento, ou seja, sabem que a cada dia estão aprendendo novos conhecimentos, nos diferentes momentos de interação proporcionados pelo fazer-se educador/a na EFA.

Nas narrativas observou-se a importância das histórias de vida para a constituição do "ser educador/a" na EFA, como por exemplo, Souza engenheiro agrônomo desenvolveu suas habilidades como educador a partir do projeto pedagógico que orienta na EFA. Barreto, originário do campo tocantinense, também graduado em Agronomia, estudou na escola pública teve a oportunidade de uma formação acadêmica mais completa, cursando um mestrado, entretanto, continua trabalhando como educador de escolas do campo. Chaves, oriundo do ensino público cursou licenciatura e trabalhou em outros ramos profissionais como financeiro e, atualmente sente que todas as funções que trabalhou contribuem para sua atividade na EFA.

Por meio desta pesquisa na EFA "Zé de Deus", entendemos que o ponto de partida para se compreender a construção de uma identidade é a cultura, ou melhor, as diferentes culturas que proporcionam a construção de teias de significados que, ora são individuais, ora são partilhados entre educadoras/es do campo.

Sobre isso, observamos que as/os docentes demonstraram respeito pelas culturas dos educandas/os, e que o ensino ministrado pelas/os mesmas/os vem contribuindo com a formação de jovens críticos. Sem dúvida, o teórico que nos deu a dimensão e a consciência para valorizar o que aprendemos e buscamos compreender foi Paulo Freire $(2011,2018)$ que, com sua epistemologia nos fez perceber que o caminho para uma educação cidadã, justa, crítica e democrática é longo, cheio de dificuldades, mas que não podemos desistir, visto que a educação é a base da sociedade e a oferta de diferentes oportunidades para o "ser mais" depende do caminho de liberdade e equidade traçado.

Ouvimos histórias de vida distintas, mas que se encontraram ao compreenderem que a educação na EFA "Zé de Deus" deve estar vinculada ao afeto; às ações dialógicas; à prática libertadora; ao querer bem a/o educanda/o e suas famílias; à responsabilidade de formar homens e mulheres não só a partir da dimensão técnica, mas também humana, social, cultural e política.

Alguns achados desta pesquisa podem ser assim resumidos: 1) O lugar de atuação profissional interfere no modo de ser professor; 2) A entrada na profissão docente nem sempre é por um desejo inicial, às vezes é por uma desilusão, necessidade ou por afinidade; 3) A educação é uma ponte para o crescimento humano em vários aspectos; 4) Nenhuma cultura é menor ou maior que outra; assim também é a identidade, que é construída a partir de elementos diversos, durante nossas histórias de vida.

Ao finalizar esta pesquisa, pudemos conhecer a EFA "Zé de Deus" que é, acima de tudo, uma conquista para a população do campo Tocantinense. Compreendemos que 0 importante na relação pessoal e profissional é o autoconhecimento que nos permite (re)conhecer-se como pessoas e como profissionais. Para compreender como se construiu a identidade docente na EFA "Zé de Deus" foi fundamental a leitura do plano de curso da escola e verificar a função da "pedagogia da altemância", bem como da 
intenção de profissionalizar educandos, a partir da humanização, sem desvinculá-los de seu contexto. Observamos que isso perpassa também, pela construção da identidade docente a fim de conduzir o aprendizado e a construção de conhecimentos, atitudes e práticas que sejam pertinentes e relevantes à vida dos educandos do campo.

\section{REFERÊNCIAS}

ALBERTI, Verena. Fontes Orais. História dentro da História. In: PINSKY, Carla Bassanezi (Org.). Fontes Orais. São Paulo: Contexto, 2005, p. 155-202.

ARROYO. Miguel Gonzalo. Pedagogia do Oprimido. In: CALDART, Roseli Salete; PEREIRA, Isabel Brasil; FRIGOTTO, Gaudêncio (Orgs.). Dicionário da educação do campo. Rio de Janeiro, São Paulo: Escola Politécnica de Saúde Joaquim Venâncio, Expressão Popular, 2012.

ARROYO, Miguel Gonzalo. Ofício de Mestre: imagens e autoimagens. 12. ed. Petrópolis, RJ: Vozes 2010.

CALDART, Rosely Salete. Educação do campo: Notas para uma análise de percurso. Revista Trabalho, Educação e Saúde. Rio de Janeiro, v. 7 n. 1, p. 35-64, mar/jun. 2009.

CORDEIRO, Georgina N.K., REIS, Neila da Silva, HAGE, Salomão Mufarrej. Pedagogia da Alternância e seus desafios para assegurar a formação humana dos sujeitos e a sustentabilidade do campo. Em Aberto, Brasília, v. 24, n. 85, p. 115-125, abr. 2011.

FERNANDES, Bernardo Mançano; CERIOLI, Paulo Ricardo; CALDART, Rosely Salete. Primeira Conferência Nacional "Por uma educação Básica do campo". In: ARROYO, Miguel Gonzalez; CALDART, Rosely Salete; MOLINA, Mônica Castagna (Orgs.). Por uma educação do campo. Petrópolis, RJ, Editora Vozes, 2009.

FREIRE, Paulo. Pedagogia do oprimido. 50. ed. Paz e Terra: Rio de Janeiro, 2011.

FREIRE, Paulo. Pedagogia da autonomia: saberes necessários à prática educativa. 56. ed. Rio de Janeiro. Paz e Terra, 2018.

HALL, Stuart. A identidade cultural na pós-modernidade. Rio de Janeiro: DP\&A, 2006.

HALL, Stuart. Quem Precisa de Identidade? In: SILVA, Tomaz Tadeu da (Org.) Identidade e Diferença: a perspectiva dos estudos culturais. 15. ed. Petrópolis, RJ: Vozes, 2014.

MOITA, Maria da conceição. Percurso de Formação e de Transformação. In: NÓVOA, Antônio. Vidas de Professores. Porto: Porto Editora, 2013, p.111-139.

MOLINA, Mônica Castagna; JESUS, Sonia Meire Santos Azevedo de. (Orgs.) Contribuições para a construção de um projeto de Educação do Campo. Brasília, DF: articulação nacional Por Uma Educação do Campo, n 5, 2004.

MONTENEGRO, Antônio Torres. História oral e memória: a cultura popular revisitada. 5.ed. São Paulo: Contexto 2003.

ROCHA-ANTUNES, Maria Isabel; MARTINS, Maria de Fátima Almeida. Tempo Escola e Tempo Comunidade: Territórios Educativos na Educação do Campo. In: ROCHA-ANTUNES, Maria Isabel; MARTINS, Maria de Fátima Almeida; MARTINS Aracy Alves (Orgs.). Territórios Educativos na Educação do Campo: Escola, Comunidade e Movimentos Sociais. Belo Horizonte: Autêntica Editora, 2012.

TEIXEIRA, Edival Sebastião; BERNARTT, Maria de Lourdes; TRINDADE, Glademir Alves. Estudos sobre Pedagogia da Alternância no Brasil: revisão de literatura e perspectivas para a pesquisa. Educação e Pesquisa, v. 34, n. 2, maio-agosto, 2008, pp. 227-242.

SÁNCHEZ GAMBOA, Silvio Ancisar. Pesquisa Qualitativa: superando tecnicismos e falsos dualismos. Revista Contrapontos. v. 3. n.3 p. 393-405- Itajaí, set./dez. 2003.

SCHIMITT, Deodete Maria das Neves. Escola Família Agrícola Zé de Deus e a formação de trabalhadores do campo em Colinas do Tocantins. 258 f. Tese (doutorado) - Programa de Pós Graduação em Educação, Universidade Metodista de Piracicaba, Piracicaba, 2017.

TOCANTINS. Plano de Curso Técnico em Agropecuária Integrado ao Ensino Médio. Escola Família Agrícola Zé de Deus. Colinas do Tocantins, 2017. 


\section{FONTES PRIMÁRIAS}

PINHO, Césio Silva. [37 anos]. [junho, 2018]. Entrevistadora: XXXXXX. Colinas, junho, 2018.

BARRETO, Evane Gentil dos Santos. [42 anos]. [junho, 2018]. Entrevistadora: XXXXXX. Colinas, junho, 2018.

SOUZA, Kelson Fiuca de. [33 anos]. [junho, 2018]. Entrevistadora: XXXXXX. Colinas, junho, 2018.

CHAVES, Pedro Alves. [53 anos]. [junho, 2018]. Entrevistadora: XXXXXX. Colinas, junho, 2018.

SILVA, Rodrigues da Cirlene. [39 anos]. [ Dezembro, 2018]. Entrevistadora: XXXXXX. Colinas, Dezembro, 2018.

ABREU, Dayanne Alves. [29 anos]. [Janeiro, 2019]. Entrevistadora: XXXXXX. Colinas, Janeiro, 2019.

Data da submissão: $17 / 08 / 2020$

Data da aprovação: 12/12/2020 